Supporting Information for

\title{
Vapor-Phase Atomic Layer Deposition of Nickel Sulfide and Its Application for Efficient Oxygen-Evolution Electrocatalysis
}

\author{
Hao Li, ${ }^{\dagger}$ Youdong Shao, ${ }^{\dagger}$ Yantao Su, Yuanhong Gao and Xinwei Wang* \\ School of Advanced Materials, Shenzhen Graduate School, Peking University, Shenzhen \\ 518055, China \\ ${ }^{\dagger}$ These authors contributed equally. \\ *Corresponding email: wangxw@pkusz.edu.cn
}




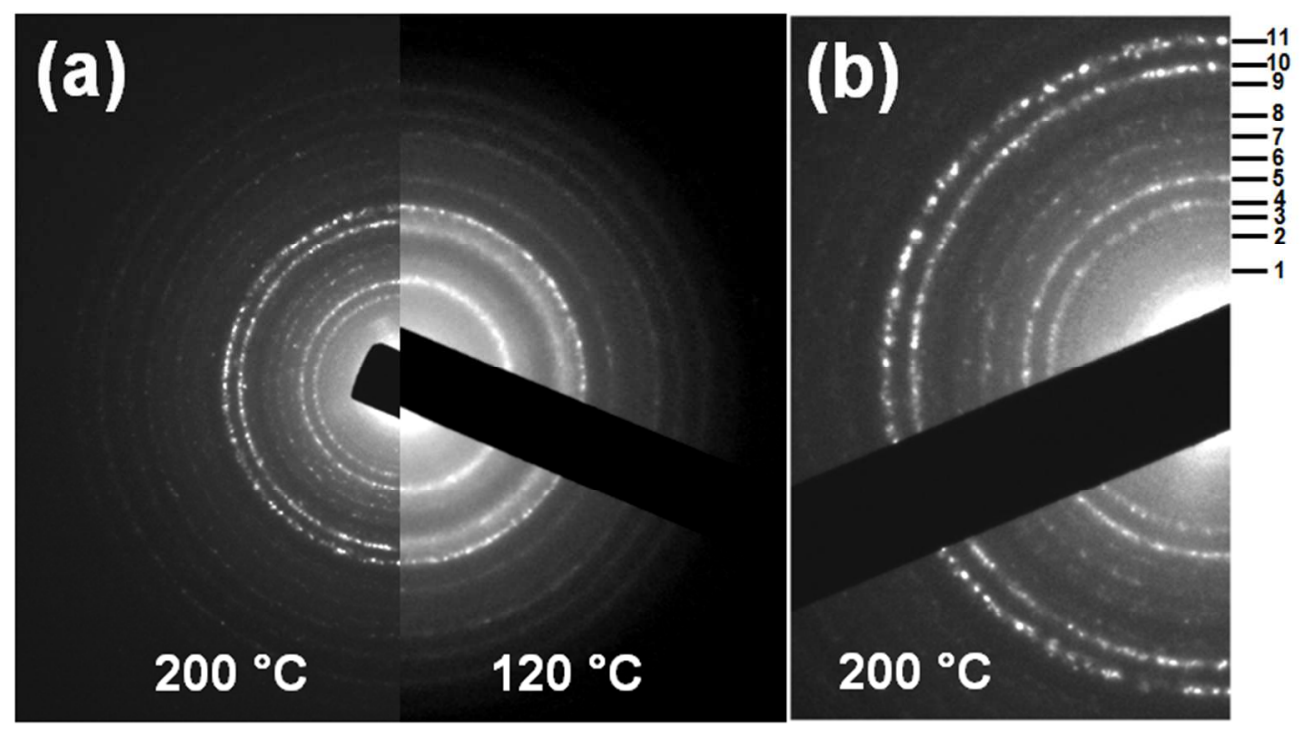

Figure S1. (a) Side-by-side comparison of the electron diffraction patterns for the $\mathrm{NiS}_{\mathrm{x}}$ films deposited at 200 and $120{ }^{\circ} \mathrm{C}$ (reproduced from Figure 2b,d), showing that they shared the same crystal structure. (b) labeling of the diffraction rings. The labeled numbers are used in Table S1 for identifying the Miller indices for these diffraction rings. 
Table S1. Comparison of the d-spacings for the godlevskite $\mathrm{Ni}_{9} \mathrm{~S}_{8}$ structure from the database (PDF\#22-1193) and the values measured by TEM. The label numbers shown in the last column correspond to the labels of the diffraction rings in Figure S1b.

\begin{tabular}{|c|c|c|c|c|}
\hline \multirow[b]{2}{*}{ (h k I) } & \multicolumn{2}{|c|}{ PDF\#22-1193 } & \multicolumn{2}{|c|}{ TEM results } \\
\hline & $d(\AA)$ & Intensity & Measured d $(\AA)$ & $\begin{array}{l}\text { Label No. in } \\
\text { Figure S1b }\end{array}$ \\
\hline (111) & 5.7500 & 20.0 & 5.73 & 1 \\
\hline$(002)$ & 4.7000 & 10.0 & & \\
\hline (201) & 4.1400 & 20.0 & \multirow{2}{*}{3.96} & \multirow{2}{*}{2} \\
\hline (112) & 3.9300 & 10.0 & & \\
\hline (022) & 3.6200 & 20.0 & 3.64 & 3 \\
\hline (202) & 3.2800 & 50.0 & 3.26 & 4 \\
\hline$(222)$ & 2.8500 & 100.0 & \multirow{2}{*}{2.83} & \multirow{2}{*}{5} \\
\hline (132) & 2.8000 & 20.0 & & \\
\hline (023) & 2.7500 & 20.0 & & \\
\hline (203) & 2.6200 & 10.0 & \multirow{2}{*}{2.58} & \multirow{2}{*}{6} \\
\hline (312) & 2.5000 & 10.0 & & \\
\hline$(240)$ & 2.4000 & 10.0 & & \\
\hline (330) & 2.3700 & 10.0 & & \\
\hline (241) & 2.3300 & 40.0 & \multirow{2}{*}{2.29} & \multirow{2}{*}{7} \\
\hline (114) & 2.2400 & 10.0 & & \\
\hline (024) & 2.1800 & 40.0 & \multirow{3}{*}{2.13} & \multirow{3}{*}{8} \\
\hline (332) & 2.1200 & 10.0 & & \\
\hline (043) & 2.1000 & 50.0 & & \\
\hline (422) & 1.9410 & 20.0 & \multirow{2}{*}{1.94} & \multirow{2}{*}{9} \\
\hline (243) & 1.9060 & 30.0 & & \\
\hline (115) & 1.8320 & 30.0 & \multirow{3}{*}{1.80} & \multirow{3}{*}{10} \\
\hline (153) & 1.8030 & 90.0 & & \\
\hline (025) & 1.7950 & 80.0 & & \\
\hline (261) & 1.7140 & 10.0 & & \\
\hline (530) & 1.6540 & 80.0 & \multirow{2}{*}{1.64} & \multirow{2}{*}{11} \\
\hline (531) & 1.6250 & 30.0 & & \\
\hline
\end{tabular}


(a)

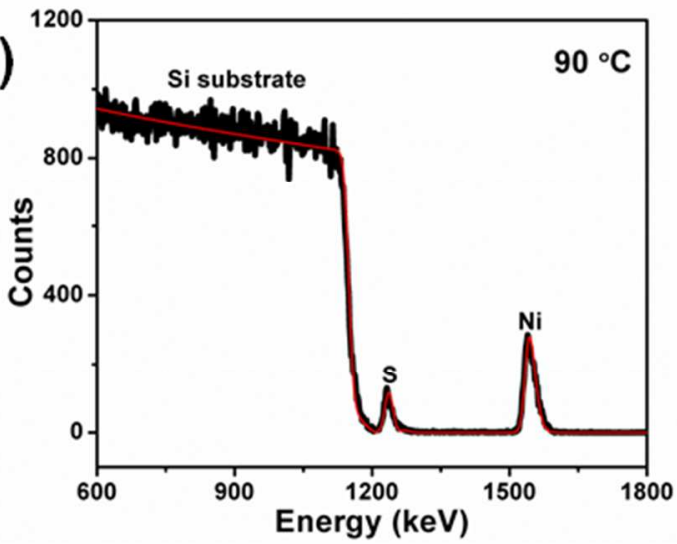

(b)
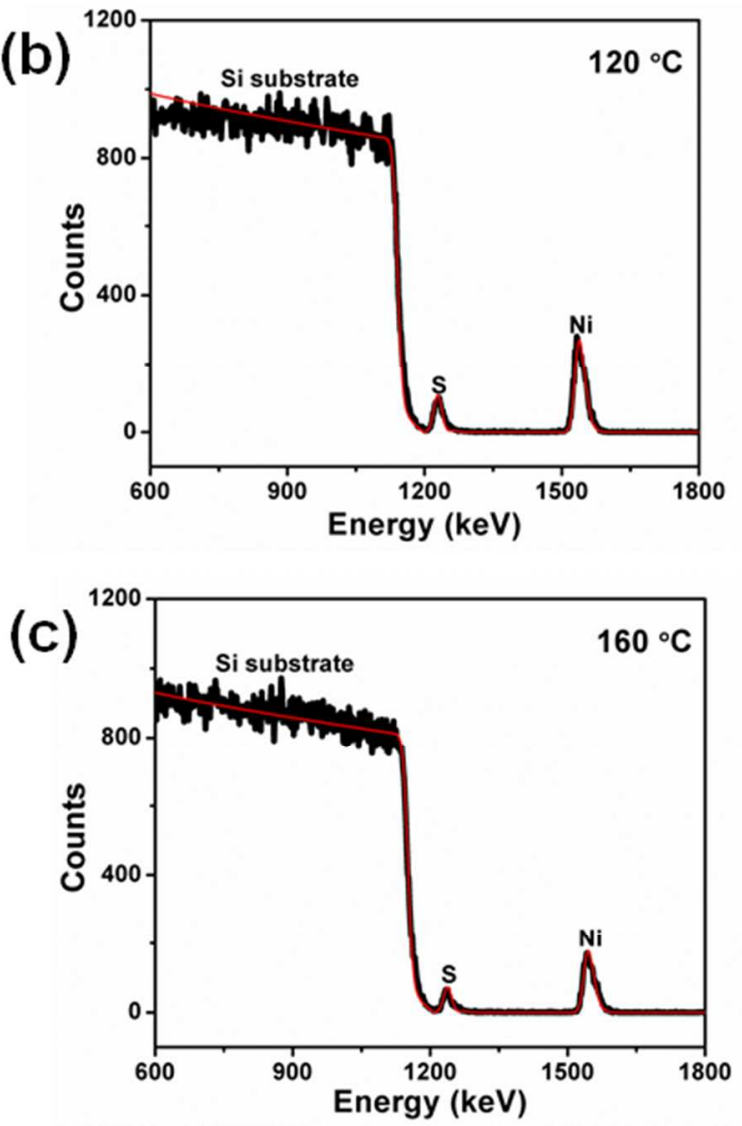

Figure S2. Experimental (black) and simulated (red) RBS spectra for $\mathrm{NiS}_{\mathrm{x}}$ films deposited at (a) $90{ }^{\circ} \mathrm{C}$, (b) $120{ }^{\circ} \mathrm{C}$, and (c) $160{ }^{\circ} \mathrm{C}$, respectively. The simulated film thicknesses were (a) $10.4 \mathrm{~nm}$, (b) $9.1 \mathrm{~nm}$, and (c) $5.2 \mathrm{~nm}$, respectively. The obtained Ni/S ratios were plotted in Figure $3 b$. 

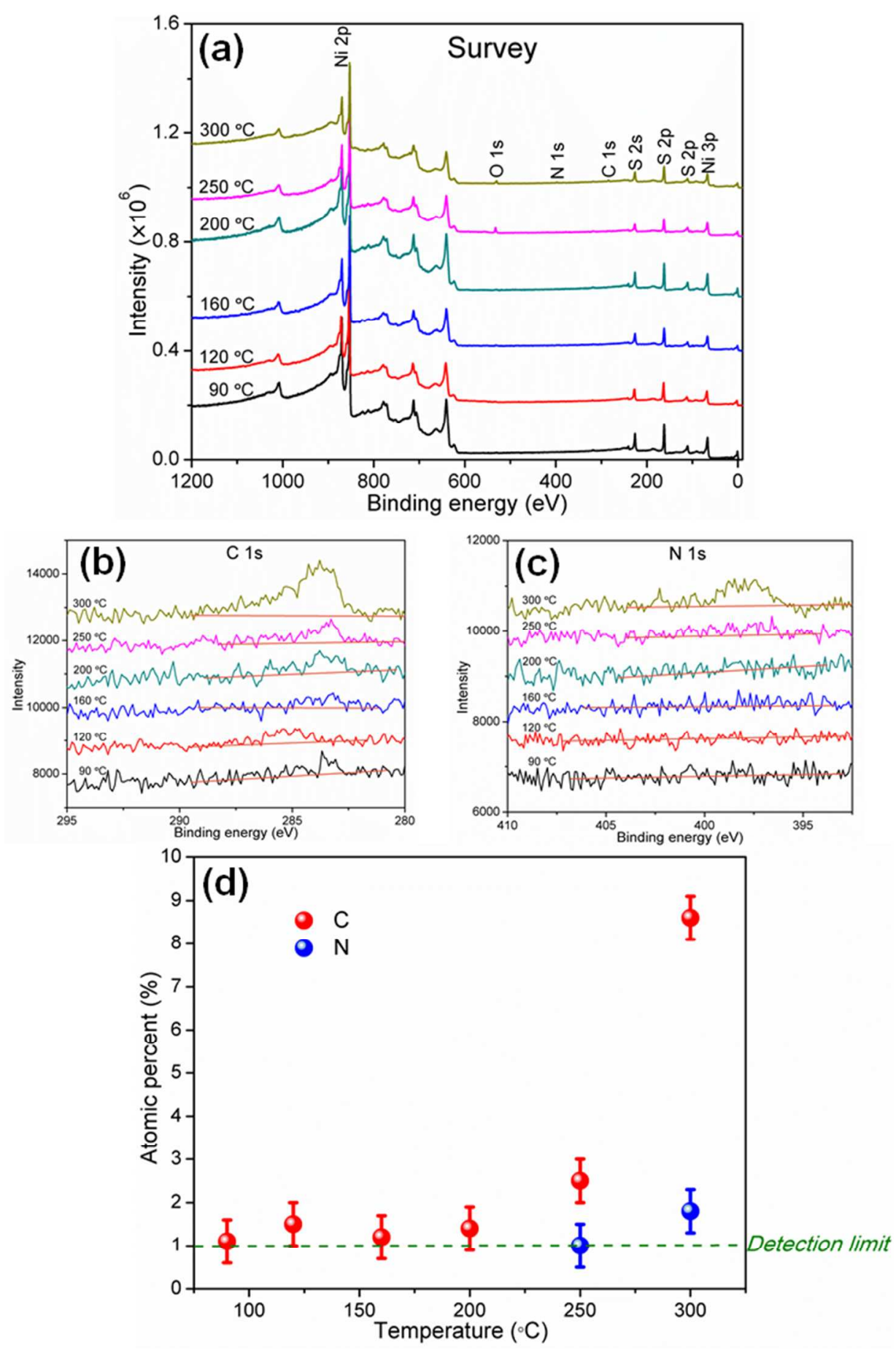

Figure S3. Additional XPS spectra for the films deposited at various temperatures: (a) survey scans, and high-resolution scans for (b) carbon and (c) nitrogen. (d) plot of the impurity levels for carbon and nitrogen with various deposition temperatures. 

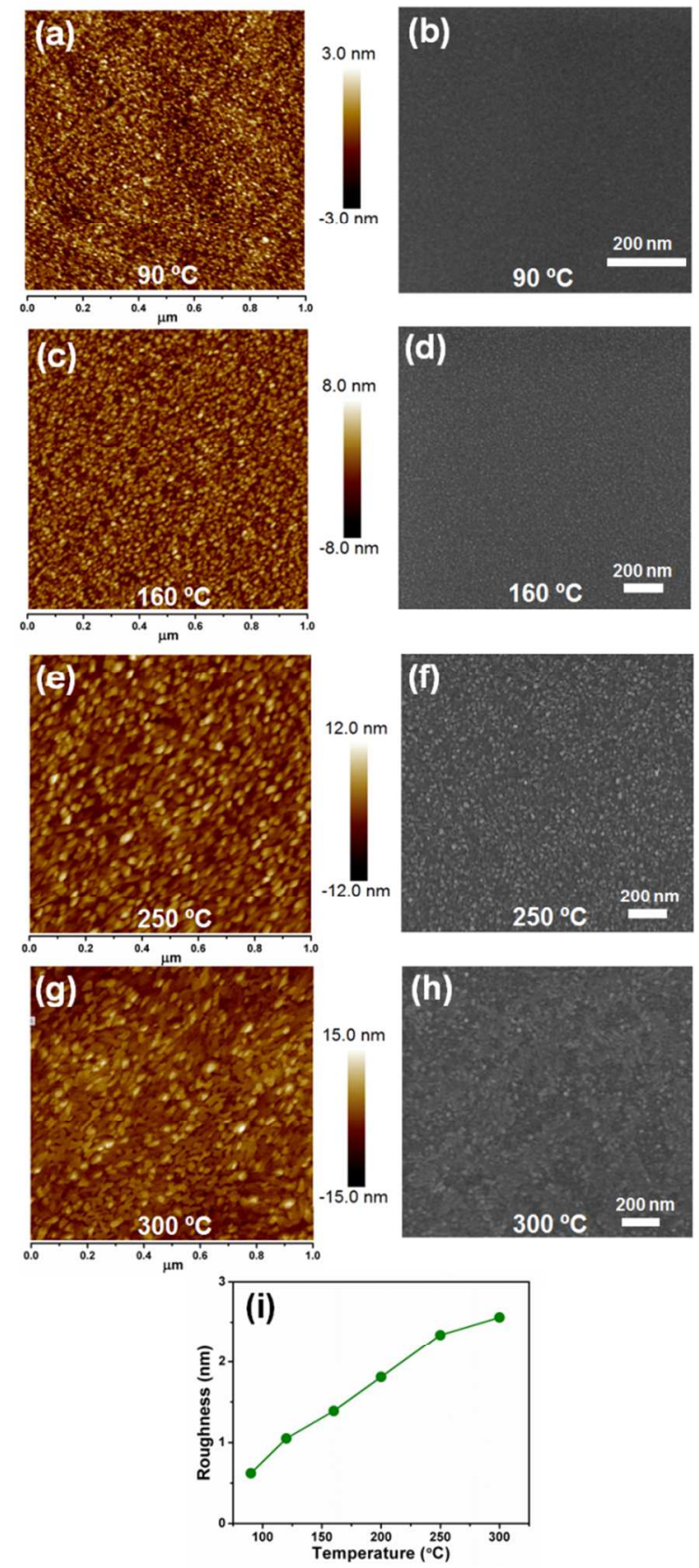

Figure S4. (a, c, e, g) AFM and (b, d, f, h) SEM images of $\sim 10 \mathrm{~nm} \mathrm{NiS} \mathrm{x}_{\mathrm{x}}$ films deposited at various temperatures of $(\mathrm{a}, \mathrm{b}) 90{ }^{\circ} \mathrm{C}$, (c, d) $160{ }^{\circ} \mathrm{C},(\mathrm{e}, \mathrm{f}) 250{ }^{\circ} \mathrm{C}$, and $(\mathrm{g}, \mathrm{h}) 300{ }^{\circ} \mathrm{C}$, respectively. (i) plot of the rms roughness obtained from the AFM images as a function of deposition temperature. The roughness values from the AFM images in Figure $4 a-b$ were also included in the plot. 


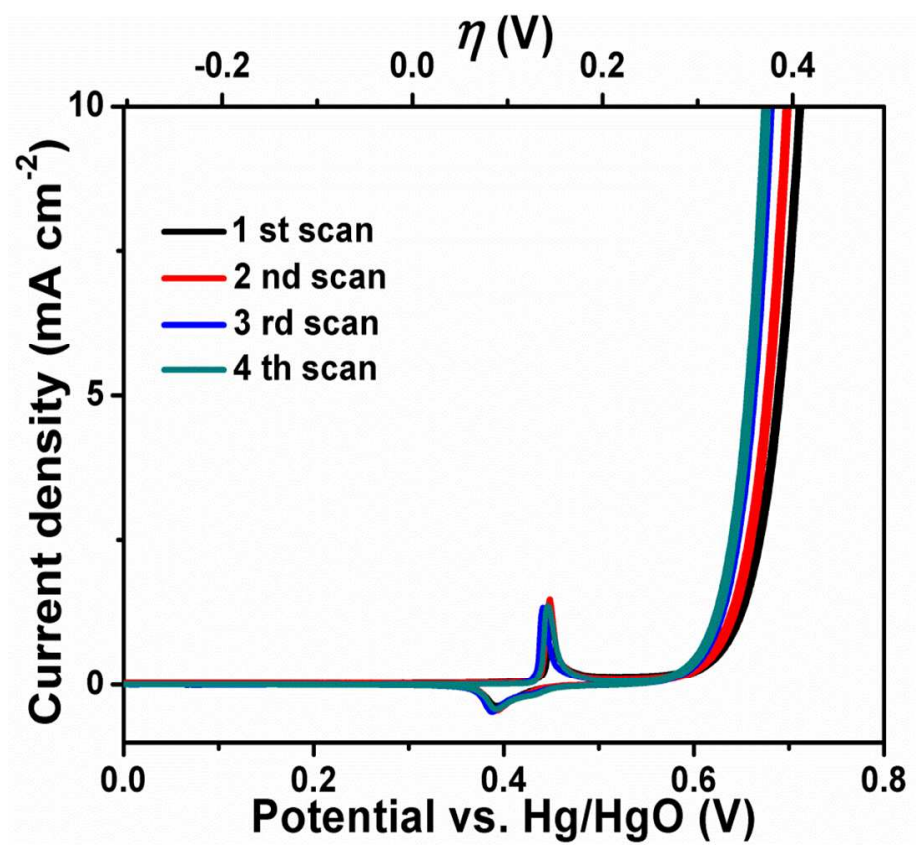

Figure S5. First four CV scans for the as-deposited $\mathrm{NiS}_{\mathrm{x}}$ film (scan rate was $2 \mathrm{mV} / \mathrm{s}$ ). The OER overpotential corresponding to $10 \mathrm{~mA} / \mathrm{cm}^{2}$ current density continually decreased. 


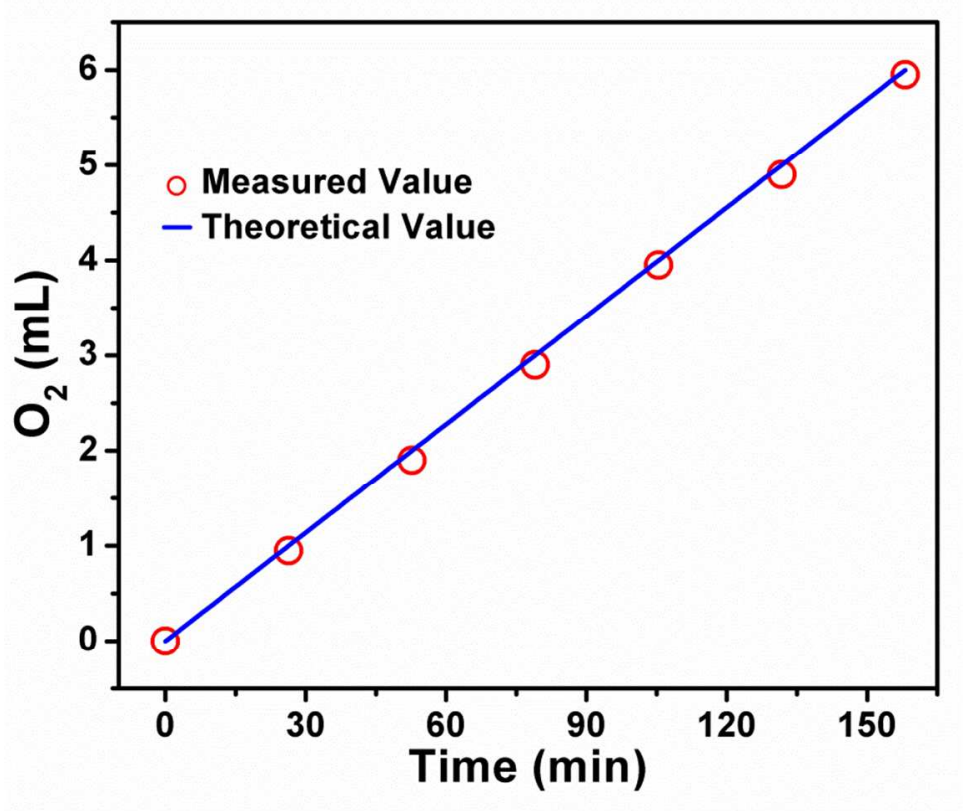

Figure S6. Comparison of the $\mathrm{O}_{2}$ volume experimentally produced and the theoretical value calculated based on 100\% Faradaic efficiency. The good overlap of these two sets of data indicates that the OER Faradaic efficiency was $\sim 100 \%$. Constant current of 10 $\mathrm{mA}$ was used for this experiment, and the evolved $\mathrm{O}_{2}$ volume was measured by water drainage method (J. Am. Chem. Soc. 2015, 137, 14023-14026). 

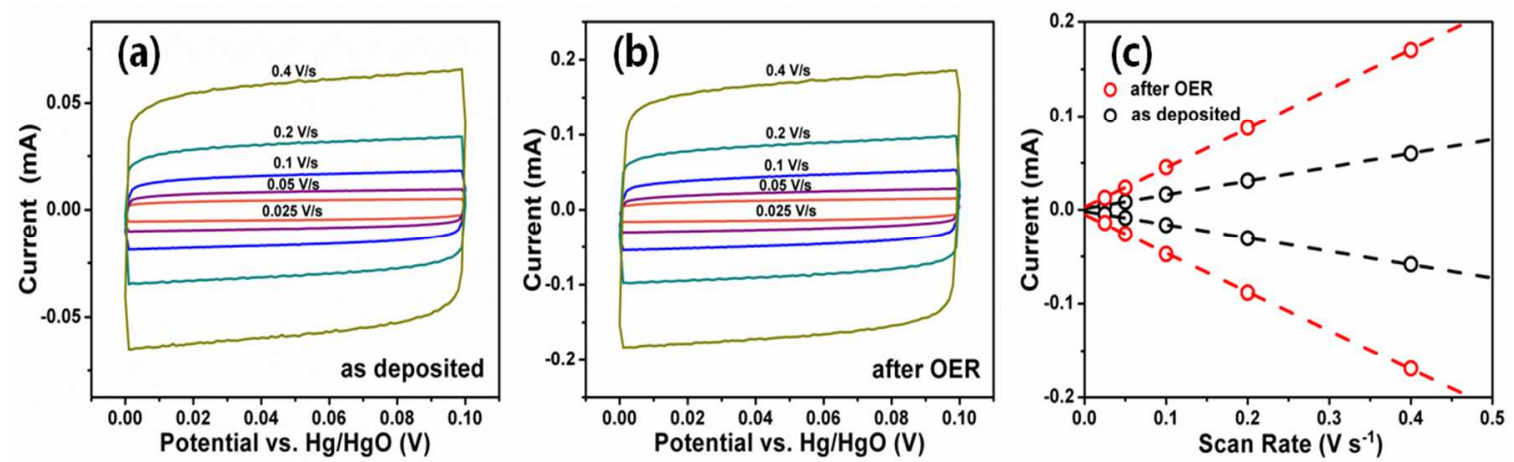

Figure S7. CV curves for the (a) as-deposited and (b) after-OER films measured in 1M $\mathrm{KOH}$. (c) Plot of current with respect to scan rate, in which the electrical double layer capacitance of the electrode/electrolyte interface were extracted, from the slopes of the linear fit, as 0.145 and $0.415 \mathrm{mF}$ for the as-deposited and after-OER films, respectively. 

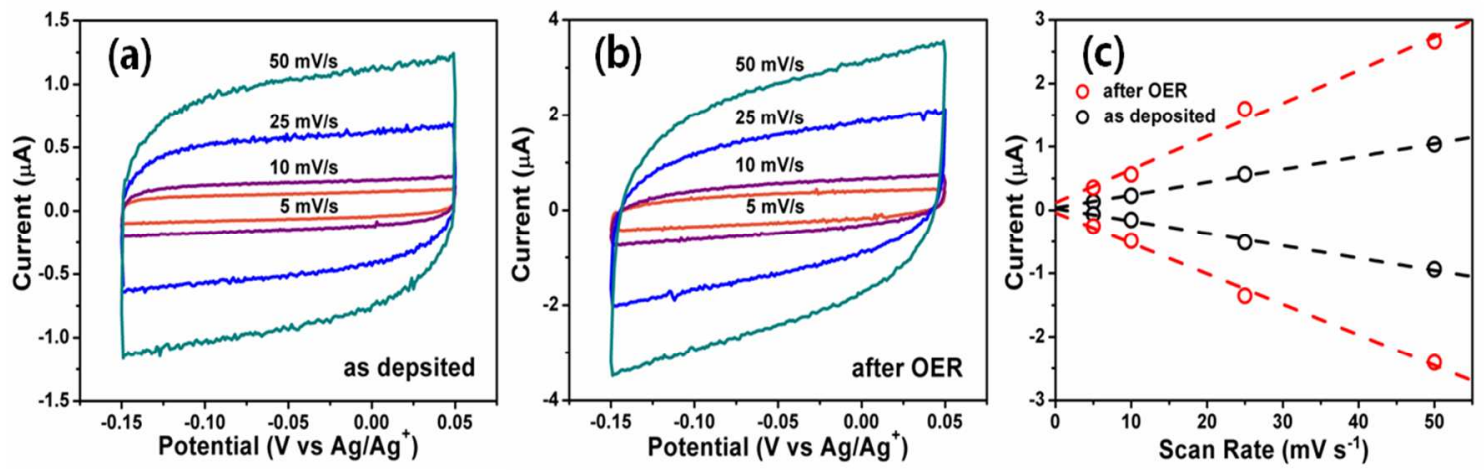

Figure S8. CV curves for the (a) as-deposited and (b) after-OER films measured in $0.1 \mathrm{M}$ tetrabutylammonium hexafluorophosphate in acetonitrile $\left(\mathrm{TBAPF}_{6} / \mathrm{CH}_{3} \mathrm{CN}\right) . \mathrm{TBAPF}_{6}$ serves as an aprotic electrolyte, so any possible pseudocapacitive charge transfer can be avoided. $\mathrm{Ag} / \mathrm{Ag}^{+}$was used as the reference electrode. (c) Plot of current density with respect to scan rate, in which the electrical double layer capacitance of the electrode/electrolyte interface were extracted, from the slopes of the linear fit, as 0.0199 and $0.0502 \mathrm{mF}$ for the as-deposited and after-OER films, respectively. 


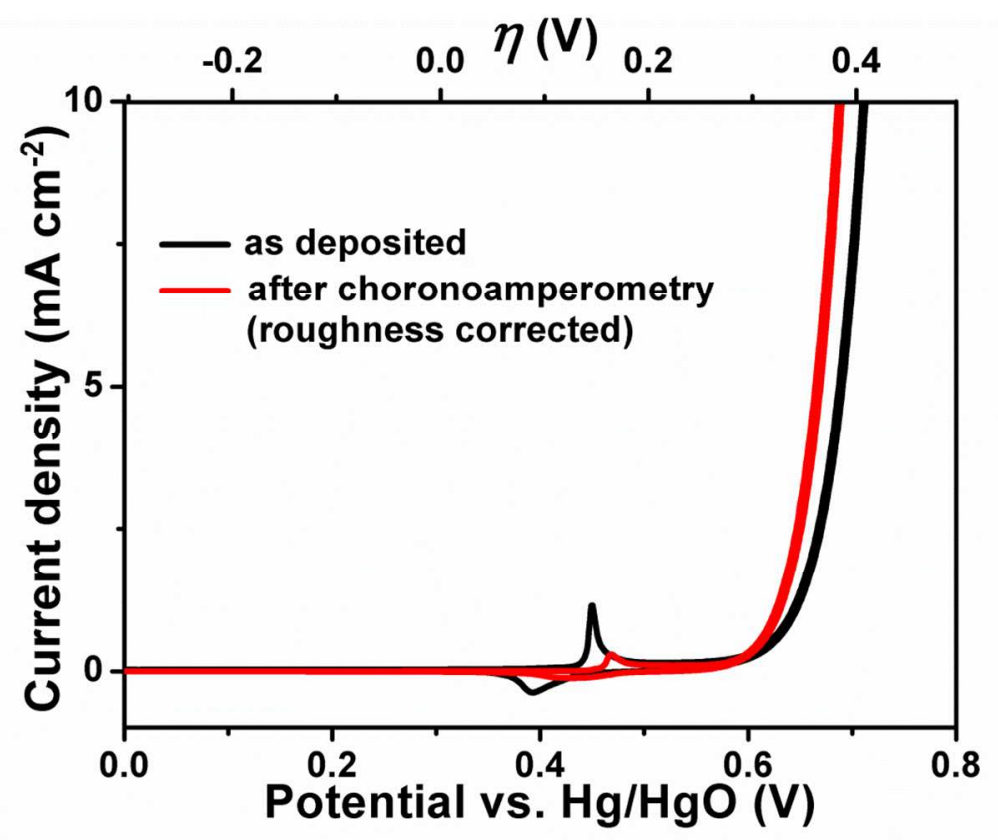

Figure S9. To better compare the specific activity of the $\mathrm{NiS}_{\mathrm{x}}$ material before and after OER aging, the increase of the film roughness should be corrected. Therefore, the polarization curve for the "after chronoamperometry" case (Figure 5a) was divided by the roughness-enhancement factor of $0.415 / 0.145$, and corrected curve (red) still showed better catalytic performance than the "as deposited" curve (black). 


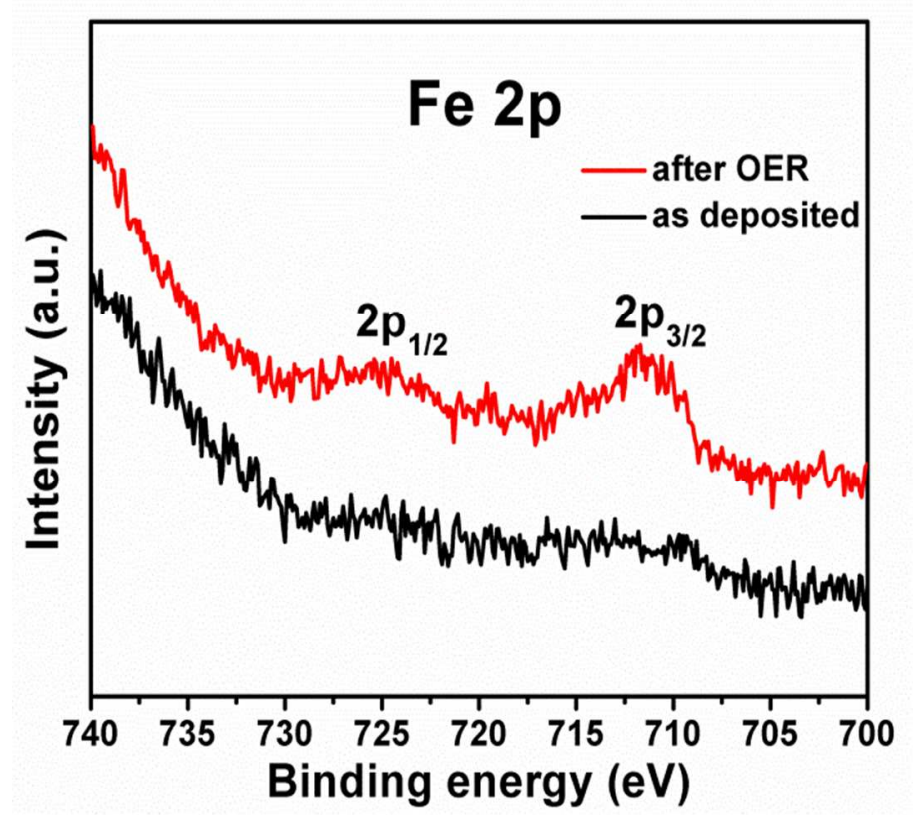

Figure S10. Comparatively showing the change of XPS Fe $2 p$ peaks for the ALD film before and after OER. Since the Fe content was expected to be in trace amount, and the main $\mathrm{Fe}$ peaks (i.e. Fe 2p) overlap with the Ni Auger peaks, we instead used the nonmonochromated $\mathrm{Mg} \mathrm{K} \alpha$ radiation from a twin anode as the $\mathrm{X}$-ray source. 


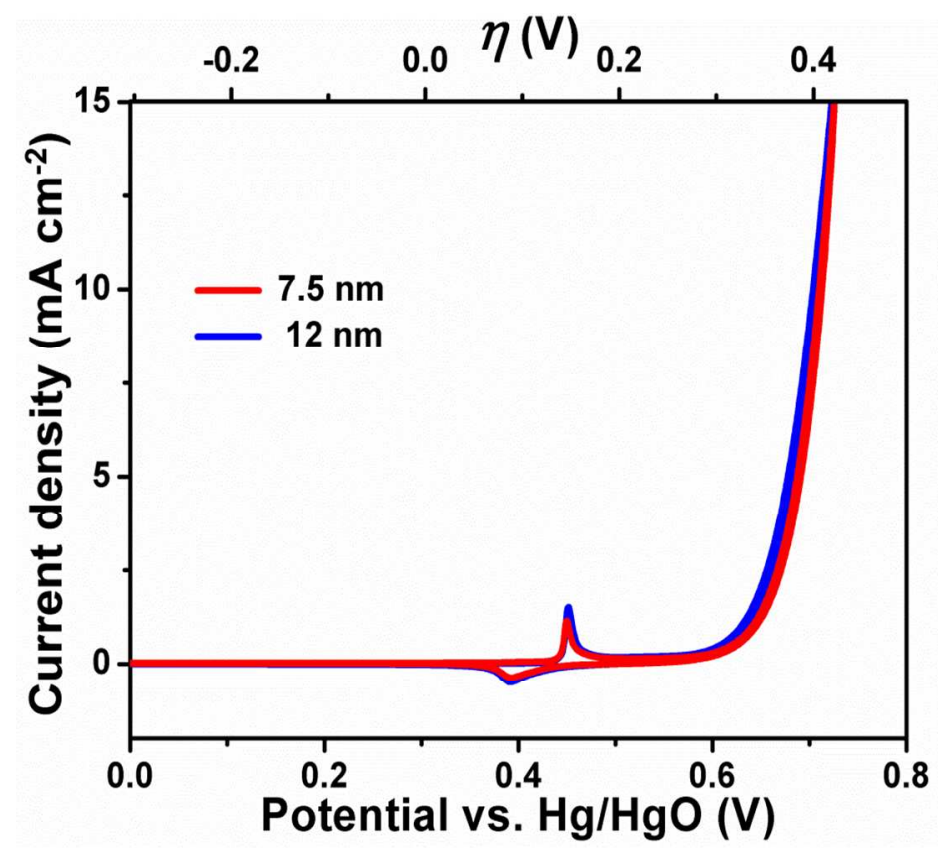

Figure S11. Comparison of the CV scans $(2 \mathrm{mV} / \mathrm{s})$ for ALD NiS $\mathrm{S}_{\mathrm{x}}$ films with different thicknesses $(7.5 \mathrm{~nm}$ and $12 \mathrm{~nm})$. 